\title{
Green Synthesis, Characterization, and Antibacterial Activity of Silver/Polystyrene Nanocomposite
}

\author{
Manal A. Awad, ${ }^{1}$ W. K. Mekhamer, ${ }^{2}$ Nada M. Merghani, ${ }^{3}$ Awatif A. Hendi, ${ }^{4}$ \\ Khalid M. O. Ortashi, ${ }^{5}$ Fatimah Al-Abbas, ${ }^{2}$ and Nada E. Eisa ${ }^{6}$ \\ ${ }^{1}$ King Abdullah Institute for Nanotechnology, King Saud University, Riyadh 11321, Saudi Arabia \\ ${ }^{2}$ Chemistry Department, Faculty of Science, King Saud University, Riyadh 11321, Saudi Arabia \\ ${ }^{3}$ Central Lab, College of Science, King Saud University, Riyadh 11321, Saudi Arabia \\ ${ }^{4}$ Physics Department, Faculty of Science, King Saud University, Riyadh 11321, Saudi Arabia \\ ${ }^{5}$ Department of Chemical Engineering, King Saud University, Riyadh 11421, Saudi Arabia \\ ${ }^{6}$ Department of Physics, University of Dammam, P.O. Box 1982, Dammam 31441, Saudi Arabia
}

Correspondence should be addressed to Manal A. Awad; a.manalawad@gmail.com and Awatif A. Hendi; ahindi@ksu.edu.sa

Received 18 April 2015; Revised 3 June 2015; Accepted 22 July 2015

Academic Editor: Bin Li

Copyright (C) 2015 Manal A. Awad et al. This is an open access article distributed under the Creative Commons Attribution License, which permits unrestricted use, distribution, and reproduction in any medium, provided the original work is properly cited.

A novel, nontoxic, simple, cost-effective and ecofriendly technique was used to synthesize green silver nanoparticles (AgNPs). The AgNPs were synthesized using orange peel extract as a reducing agent for silver nitrate salt $\left(\mathrm{AgNO}_{3}\right)$. The particle size distribution of AgNPs was determined by Dynamic Light Scattering (DLS). The average size of silver nanoparticles was $98.43 \mathrm{~nm}$. The stable dispersion of silver nanoparticles was added slowly to polystyrene solution in toluene maintaining the temperature at $70^{\circ} \mathrm{C}$. The AgNPs/polystyrene (PS) nanocomposite solution was cast in a petri dish. The silver nanoparticles encapsulated within polymer chains were characterized by X-ray diffraction (XRD) and Scanning Electron Microscopy (SEM) equipped with Energy Dispersive Spectroscopy (EDS) in addition to Transmission Electron Microscopy (TEM). The green AgNPs/PS nanocomposite film exhibited antimicrobial activity against Gram-negative bacteria Escherichia coli, Klebsiella pneumoniae and Salmonella, and Gram-positive bacteria Staphylococcus aureus. Thus, the key findings of the work include the use of a safe and simple AgNPs/PS nanocomposite which had a marked antibacterial activity which has a potential application in food packaging.

\section{Introduction}

The nanomaterials can be synthesized by different methods including chemical, physical, and biological methods. The development of new chemical or physical methods has resulted in environmental contamination, since the chemical procedures involved in the synthesis of nanomaterials generate a large amount of hazardous byproducts [1]. Thus, there is a need for "green nanotechnology" that includes a clean, safe, ecofriendly, and nontoxic method of nanoparticle synthesis, without the use of high pressure, energy, temperature, and toxic chemicals [2]. The biological methods include synthesis of nanomaterials from the extracts of plant, bacterial, fungal species, and so forth [3].

Nanoparticles of silver have been found to exhibit interesting antibacterial activity [4], and the investigation of this phenomenon has gained importance due to the increase of bacterial resistance to antibiotics, caused by their overuse. Recently, materials have been developed (mainly textiles) containing silver nanoparticles, which exhibit very interesting antimicrobial activity. Antibacterial activity of the plasticcontaining silver can be used, for example, in medicines to reduce infections as well as preventing bacteria colonization on plastic devices such as prostheses, catheters, vascular grafts, and dental materials [5]. Under ideal temperature and humidity conditions, plastics can be a good medium for the generation and the propagation of microorganisms which can cause irritations and infections. For these reasons, the polymeric materials must be protected against microorganisms in order to suppress their growth and dissemination. Owing to the high antimicrobial activity, relatively low cost, and easy production in a polymer-embedded form, nanoscopic silver could be a very adequate filler for such a purpose [6]. 
Silver nanoparticles (AgNPs) have been reported to form composites with polymers such as polyvinyl alcohol, polypyrrole, polyvinylidene fluoride, chitosan, and cellulose. The formation of polymer-silver nanocomposites requires that the size of nanoparticles in the polymer matrix be controllable and that their distribution within the polymer matrix be uniform [7]. Many previous attempts to form polymer-silver nanocomposites have involved mixing of a nanoparticle solution into the polymerization mixture. These polymer-silver nanocomposites can be used in a wide range of biomedical products, such as surgical gloves, antibacterial cloths and towels, and anti-infectious urinary catheters [8]; also they can be incorporated into aseptic coverings for plastic surgery, traumatic wounds, leg ulcers, skin grafts, incisions, and abrasions. Further, they can be used in numerous household applications such as textiles disinfection in water treatment, food storage containers, and home appliances and in medical devices [9].

The idea of the present study was green synthesis of AgNPs by chemical reduction of silver nitrate using orange peel extract as a reducing agent, and the preparation of AgNPs/polystyrene nanocomposite film. In addition, to study the antimicrobial potential of a silver-polystyrene nanocomposite system. To the best of our knowledge, this is the first study describing the preparation of silver nanoparticles using orange peel extract from toluene and their composite with polystyrene polymer.

\section{Experimental}

2.1. Chemicals Materials. For green synthesis of silver nanoparticles and silver/polystyrene nanocomposite, the reagents used were of analytical grade and were used as received without further purification. Silver nitrate $\left(\mathrm{AgNO}_{3}\right)$ was from Techno Pharmchem, India. Polystyrene was supplied by the Saudi Basic Industries Corporation (SABIC) (Saudi Arabia). The brand name for polystyrene is PS 125, with molecular weight, $259000 \mathrm{~g} /$ mole. Toluene, $\mathrm{C}_{6} \mathrm{H}_{5} \mathrm{CH}_{3}$, molecular weight $(92.14 \mathrm{~g} / \mathrm{mol})$, with $99.5 \%$ purity provided by $(\mathrm{BDH}$ Co).

2.2. Green Synthesis of Silver Nanoparticles. $200 \mathrm{mg}$ of orange peel was crushed to which $20 \mathrm{~mL}$ of toluene was added with vigorous stirring for 10 minutes at $60^{\circ} \mathrm{C}$ to prepare the extract of orange peel. The extract then was centrifuged for 5 minutes at $7000 \mathrm{rpm}$ at room temperature. Then, $1 \mathrm{mmole} / \mathrm{mL}$ silver nitrate was dissolved in $20 \mathrm{~mL}$ of toluene with vigorous stirring at $70^{\circ} \mathrm{C}$ for 5 minutes. Thereafter $5 \mathrm{~mL}$ of orange peel extract was added to the solution of silver nitrate, the color changed to brown which indicated reduction of Ag ions and the formation of silver nanoparticles.

2.3. Synthesis of Green AgNPs/PS Nanocomposite Film. Various methods are employed to prepare antimicrobial AgNPs/ PS nanocomposite [10]. In our study, solution method was used to prepare antimicrobial AgNPs/PS films. $2 \mathrm{~g}$ of Polystyrene (PS) was added to the silver nanoparticles that were dispersed in toluene and synthesized as described in the previous section. The solution was stirred under vigorous stirring at $60^{\circ} \mathrm{C}$ until PS completely dissolved. Then, the solution was cast in a glass plate and the toluene was allowed to evaporate at room temperature, to produce the nanocomposite film. The film was then removed from the glass plate after 24 hours.

2.4. Antimicrobial Study. The antibacterial activity of AgNPs/ PS nanocomposite was evaluated against Gram-negative bacteria, Escherichia coli (E. coli), Klebsiella pneumoniae, and Salmonella and Gram-positive, Staphylococcus aureus, by disc diffusion method. Nutrient agar medium plates were prepared, sterilized, and solidified. After solidification, bacterial cultures were swabbed on these plates. Then, $0.5 \times$ $0.5 \mathrm{~cm}$ from pure PS, $1 \%$ AgNPs-PS nanocomposite film, and $1 \mathrm{mmole} / \mathrm{mL}$ silver nanoparticles solution were placed in the nutrient agar plate and kept for incubation at $37^{\circ} \mathrm{C}$ for 24 hours. Zones of inhibition were measured. The experiments were repeated 3 times for each sample and mean values of zone diameter were determined [10].

2.5. Characterization of AgNPs-PS Nanocomposite Film. Nanocomposite film was characterized spectrophotometrically using X-ray diffraction, Bruker D8 Discover, while the size of synthesized green AgNPs was analyzed through Zetasizer, Nano series, HT Laser, ZEN3600 (Molvern Instrument, $\mathrm{UK})$.

Transmission Electron Microscopy (JEM-1011, JEOL, Japan) was employed to characterize the size, shape, and morphologies of formed green synthesized nanocomposite accelerating voltage of 80 and $100 \mathrm{KV}$, while Thermo Scientific, Nicolet 6700, FT-IR spectrophotometer was used for recording the infrared (IR) spectrum.

Energy Dispersive Spectroscopy (EDS) analysis was performed for the confirmation of elemental silver. Elemental analysis on single particles was carried out using Oxford Instrument, Incax-act, equipped with Scanning Electron Microscopy using (JEOL-FE SEM, Japan).

\section{Results and Discussions}

3.1. X-Ray Diffraction Analysis. In this study, we described the characterization of the morphology, crystalline phase, composition, and structure of nanocomposites which was a combination of the silver nanosized powders and the (PS) polymer matrix.

Figure 1 shows XRD pattern of PS and AgNPs and AgNPs/PS nanocomposite. XRD pattern of PS shows that broad peaks appeared at $2 \theta \sim 5-20^{\circ}$ which corresponds to a mixture of ordered and disordered structure of the amorphous phase of PS [11]. The amorphous halo is caused by the spacing of individual polymer chains.

A comparison between diffraction patterns of PS and AgNPs/PS nanocomposites showed that the peaks corresponding to PS became more broader, suggesting the smaller AgNPs embedded in PS chains [12].

3.2. Particle Average Size Determination by Zetasizer. The results of DLS Zetasizer showed very homogenous distribution of AgNPs with average particle size of $45.55 \mathrm{~nm}$ which 


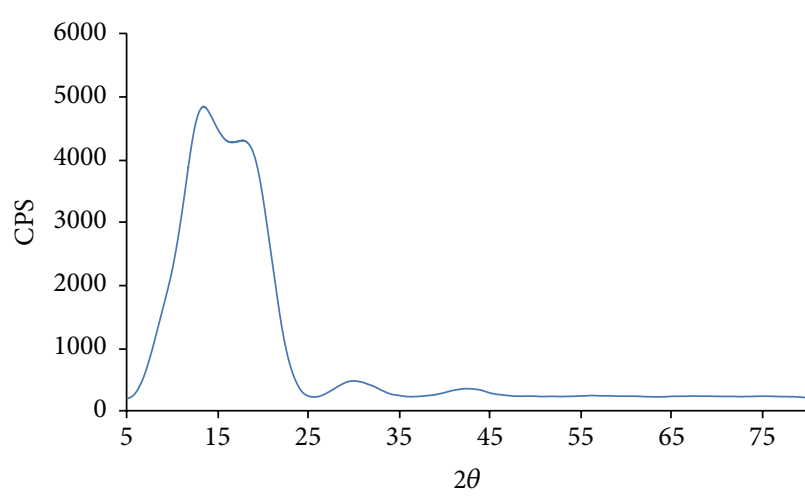

(a)

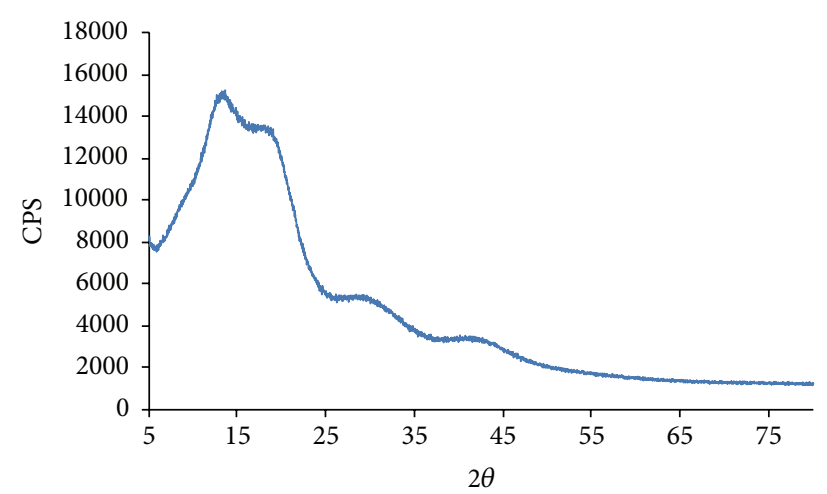

(b)

FIGURE 1: XRD pattern of PS (a) prepared film of AgNPs, PS nanocomposite (b).

\begin{tabular}{lccc} 
& Diam. $(\mathrm{nm})$ & Intensity (\%) & Width (nm) \\
\hline$Z$-average (r.nm): 98.43 & Peak 1: 45.55 & 100.0 & 8.115 \\
Pdl: 0.292 & Peak 2: 0.000 & 0.0 & 0.000 \\
Intercept: 0.971 & Peak 3: 0.000 & 0.0 & 0.000 \\
\hline
\end{tabular}

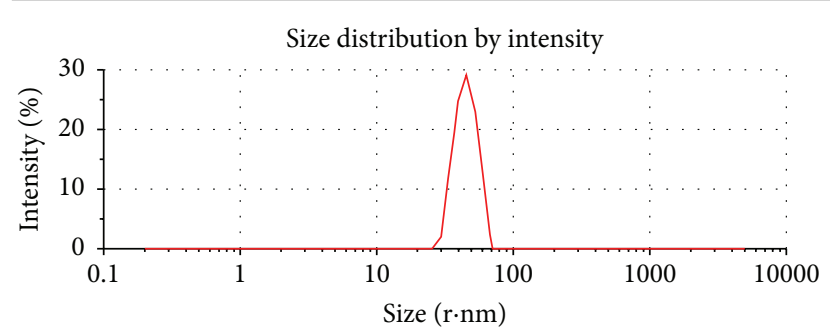

Figure 2: Particle size distribution of AgNPs.

is clearly observed from the appearance of one peak with an intensity $100 \%$ and width $8.115 \mathrm{~nm}$ as shown in Figure 2. This refers to monodispersity of nanoparticles which gives very high stability of nanoparticles for a long time. In addition, the (PDI), which is 0.292 , indicates high stability and homogeneity of the resulting AgNPs.

\subsection{TEM Analysis of Green Silver Nanoparticles and Green} Nanocomposite. TEM technique was employed to visualize the shape and morphology of green nanoparticles produced. The electron micrograph (Figure 3) confirms data obtained from the DLS. TEM micrograph of AgNPs revealed that their average size ranged between 27 and $41 \mathrm{~nm}$. Figure 3(b) shows distribution of AgNPs into the polystyrene matrix over the sample with spherical shape.

3.4. SEM and EDS Analysis of Green Silver Nanoparticles and Green Nanocomposite. Energy-dispersive spectroscopic (EDS) and SEM analysis investigated the presence of nanosilver in polystyrene matrix. The elemental analysis of AgNPs/PS nanocomposite film was studied by energy dispersive analysis of X-rays (EDS). Figure 4(b) shows EDS spectrum of AgNPs/PS nanocomposite. The peaks observed at the binding energies of $0.85,1.0$, and $3.4 \mathrm{keV}$ correspond to the binding energies of $\mathrm{C}, \mathrm{O}$, and $\mathrm{Ag}$, respectively. The presence of carbon in the EDS spectrum is related to PS. The presence of oxygen could be due to the presence of residue of the extract of the orange peel such as fatty acid. The result corroborates the formation of AgNPs/PS nanocomposite film. The SEM image of silver nanoparticles exhibits that almost all the nanoparticles are of spherical shape dispersed in polystyrene matrix with no agglomeration.

3.5. FT-IR Analysis of Green Silver Nanoparticles and Green Nanocomposite. The interfacial interaction between AgNPS/PS nanocomposites was confirmed by FT-IR spectra (Figure 5). The infrared spectrum of PS features bands at $3066 \mathrm{~cm}^{-1}, 3025 \mathrm{~cm}^{-1}, 2922 \mathrm{~cm}^{-1}$, and $2851 \mathrm{~cm}^{-1}$ due to the stretching of the (C-H) group. The peaks at 1666-1945, 1491$1599,1188-1368$, and $1026 \mathrm{~cm}^{-1}$ could be attributed to the presence of aromatic $\mathrm{C}=\mathrm{C}$ bonds stretching vibrations. The bands in the region $907-650 \mathrm{~cm}^{-1}$ can be assigned to the aromatic $\mathrm{C}-\mathrm{H}$ bonds bending vibrations. The infrared of AgNPS/PS nanocomposites spectra showed all the characteristic bands of polystyrene (PS) in addition to bands at 441.8 and $422.5 \mathrm{~cm}^{-1}$ due to Ag. Also a slight shift in the band corresponding to PS was observed indicating the interaction between PS and AgNPS.

3.6. Antibacterial Efficacy of Green Silver Nanoparticles and Green Nanocomposite. The in vitro antibacterial screening of AgNPs/PS nanocomposite was tested against gram positive Staphylococcus aureus and gram negative bacteria $E$. coli, Klebsiella pneumoniae, and Salmonella. The inhibitory activity was measured based on the diameter of the clear inhibition zone. If there was no surrounding clear zone, it was assumed that there was no inhibitory zone. Contact area was used to evaluate growth inhibition underneath. The zones of inhibition around pieces of AgNPs, pure PS film, and AgNPs/PS nanocomposite film for bacterial culture are shown in Figure 6(a) while numerical values of diameter of inhibition zones were compiled in Figure 6(b). The results exhibited very high toxicity against gram negative bacteria Escherichia coli and Salmonella, low toxicity against Klebsiella 


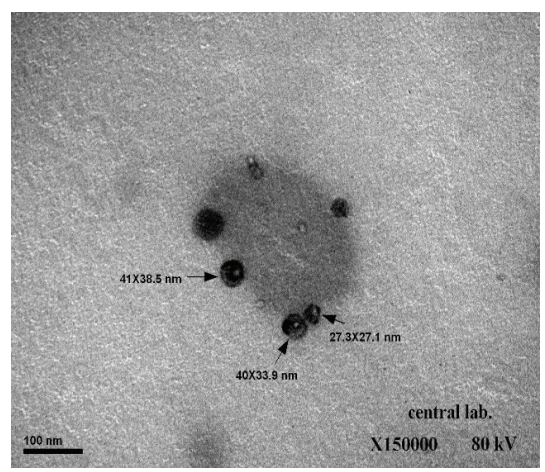

(a)

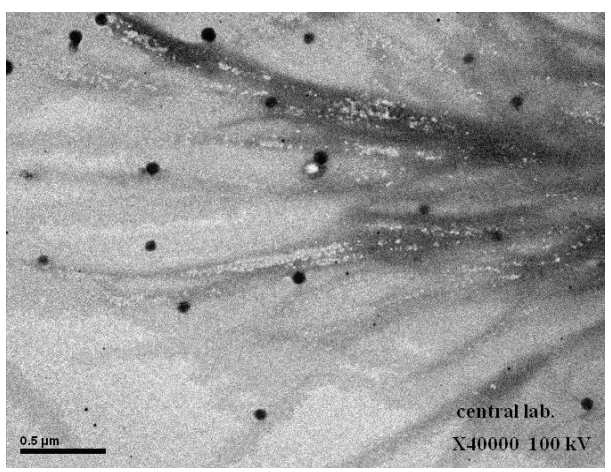

(b)

Figure 3: TEM image of AgNPs and AgNPs/PS nanocomposite from (a) to (b).

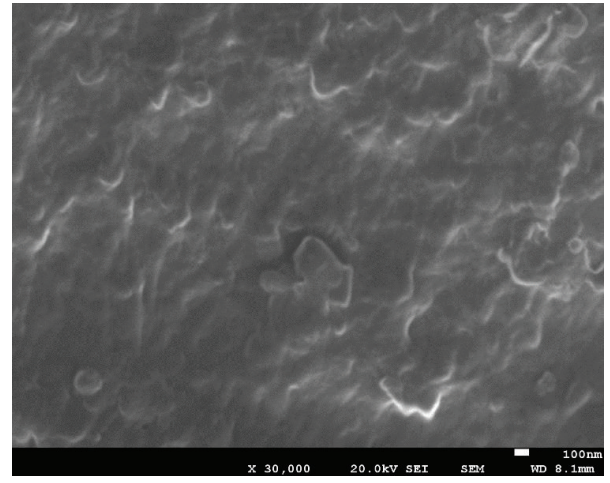

(a)

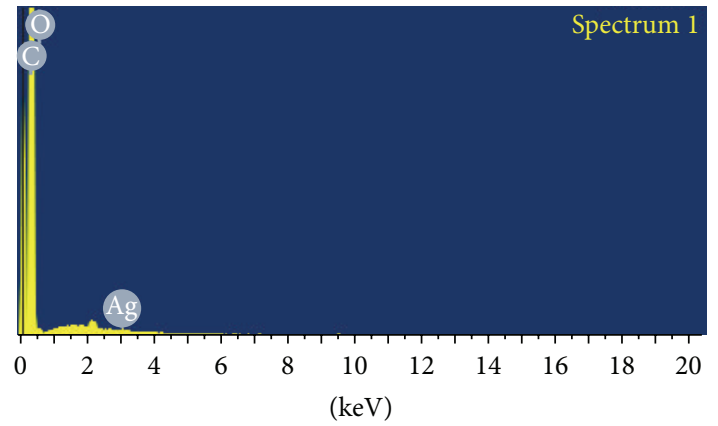

Full scale 4182 cts cursor: 0.000

(b)

FIGURE 4: SEM and EDS analysis of AgNPs/SP nanocomposite film.

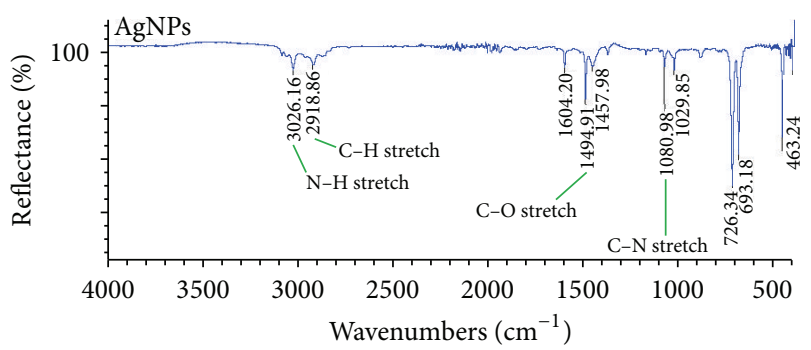

(a)

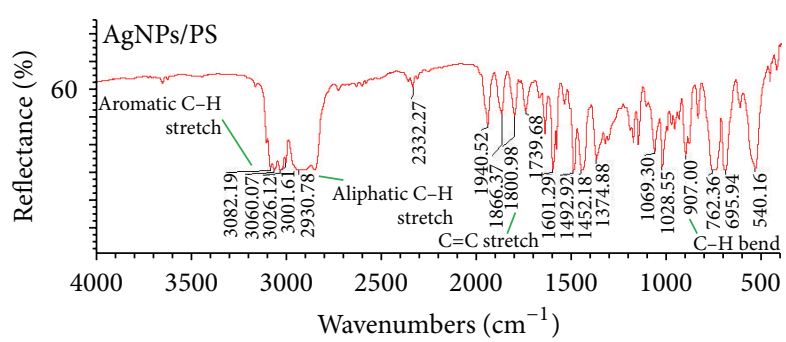

(b)

FIGURE 5: Fourier transform infrared spectra analysis for (a) AgNPs and (b) AgNPs/PS nanocomposite.

pneumoniae, and lower toxicity against gram positive bacteria Staphylococcus aureus. The presence of green AgNPs from the nanocomposite explains the antimicrobial properties found in the prepared nanocomposite. In addition to this, the antimicrobial properties that have been exhibited in our results are similar to Morones et al. [13] who reported that small size nanoparticles may pass through cell membranes generating cell malfunction [14]. It can be concluded that the nanocomposite (green AgNPs/PS) that has been prepared is an effective agent against Gram-negative and Grampositive bacteria (which is our case), taking into account that the nanoparticles are uniformly dispersed in the polyethylene matrix.

In general, the mechanism of the inhibitory effects of $\mathrm{Ag}$ ions on microorganisms is partially known. Some studies have reported that the positive charge on the Ag ion is crucial for its antimicrobial activity through the electrostatic attraction between the negative charge on the cell membrane of microorganism and positively charged nanoparticles [15-17]. In contrast, Dragieva et al. [18] reported that the antimicrobial activity of silver nanoparticles on Gram-negative bacteria was dependent on the concentration of Ag nanoparticle and 


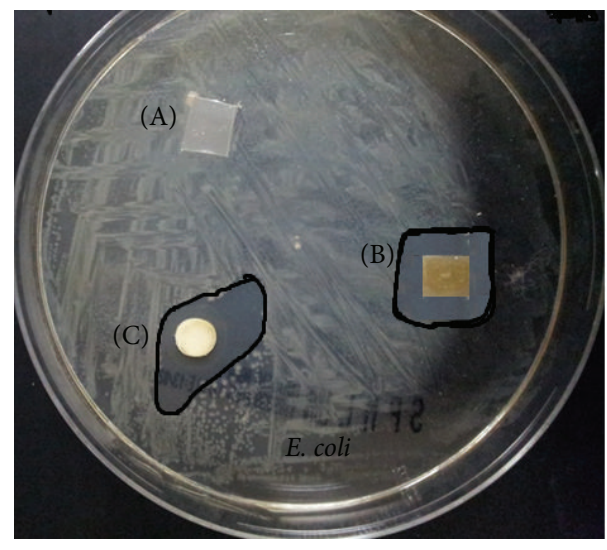

(a)

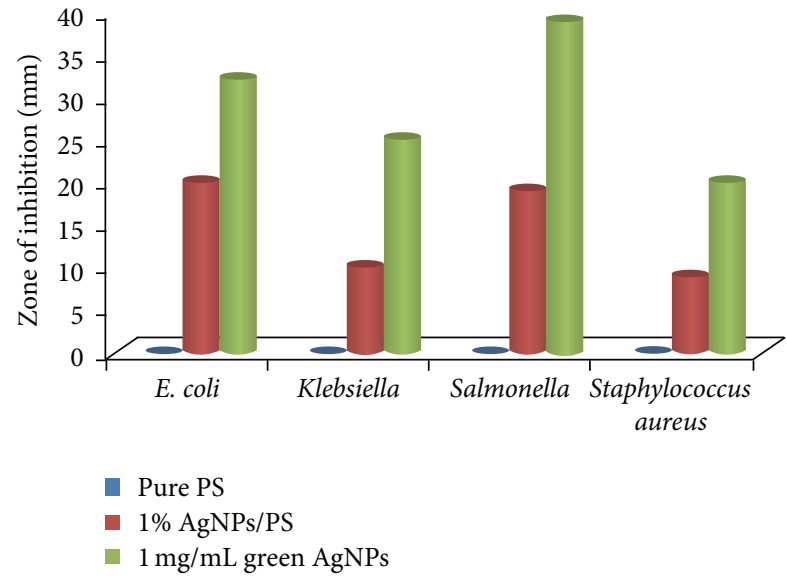

(b)

FIGURE 6: (a) Antibacterial activity assay of (A) pure PS film, (B) green AgNPs/PS nanocomposite film, and (C) green AgNPs and (b) diagram for the antibacterial activity.

was closely associated with the formation of the pits in the cell wall of bacteria. Ag nanoparticles accumulated in the bacterial membrane caused a change in the permeability, resulting in cell death. However, there studies included both positively charged Ag ions and negatively charged Ag nanoparticles; it does not explain the antimicrobial mechanism of only the positively charged Ag nanoparticles. Therefore, we expect that there is another possible mechanism. Amro et al., 2000, suggested that metal depletion may cause the formation of irregularly shaped pits in the outer membrane and change membrane permeability, which is caused by progressive release of lipopolysaccharide molecules and membrane proteins [19]. Also, Dragieva et al. speculate that a similar mechanism may cause the degradation of the membrane structure of E. coli during treatment with Ag nanoparticles [18]. Although the interference mechanism of AgNPs and bacteria involve some sort of binding mechanism, the level of that interaction between AgNPs and component(s) of the outer bacterial membrane is still not well understood.

Hence, this facile approach for synthesis of green AgNPsPS nanocomposite film can be useful in a wide range of biomedical products, such as surgical gloves, antibacterial cloths and towels, anti-infectious urinary catheters, bandage, food packaging, water container, and industrial applications. The method has been distinguish as a method which allows the use of nontoxic, abundant ecofriendly bioavailable material which is energy saving and low cost.

\section{Conclusion}

The synthesis of nanocomposite film showed significant antibacterial activity on both Gram-positive and Gram-negative bacteria. This promises a potential use of the nanocomposite in the pharmaceutical, biomedical, and industrial fields, such as bandages, wounds dressing, and dental tools. In addition, the applications include also food and water storage as well as wastewater treatment.

\section{Highlights}

(i) Silver/polystyrene nanocomposite is a novel approach.

(ii) Orange peel is extracted by toluene as a reducing agent.

(iii) Ecofriendly silver/polystyrene nanocomposite showed highly effective antibacterial activity towards Grampositive and Gram-negative bacteria.

\section{Conflict of Interests}

The authors declare that there is no conflict of interests regarding the publication of this paper.

\section{Acknowledgment}

The authors extend their appreciation to the Deanship of Scientific Research at King Saud University for funding this work through research group no. RGP-VPP-278.

\section{References}

[1] E. Amato, Y. A. Diaz-Fernandez, A. Taglietti et al., "Synthesis, characterization and antibacterial activity against gram positive and gram negative bacteria of biomimetically coated silver nanoparticles," Langmuir, vol. 27, no. 15, pp. 9165-9173, 2011. 
[2] P. Pallavicini, A. Taglietti, G. Dacarro et al., "Self-assembled monolayers of silver nanoparticles firmly grafted on glass surfaces: low $\mathrm{Ag}^{+}$release for an efficient antibacterial activity," Journal of Colloid and Interface Science, vol. 350, no. 1, pp. 110116, 2010.

[3] P. Dallas, V. K. Sharma, and R. Zboril, "Silver polymeric nanocomposites as advanced antimicrobial agents: classification, synthetic paths, applications, and perspectives," Advances in Colloid and Interface Science, vol. 166, no. 1-2, pp. 119-135, 2011.

[4] D. R. Deshmukh and R. J. Composto, "Surface segregation of silver nanoparticles in the in-situ synthesized Ag/PMMA nanocomposites," in Proceedings of the Bulletin of the American Physical Society, Baltimore, Md, USA, March 2006.

[5] C. Damm and H. Münstedt, "Kinetic aspects of the silver ion release from antimicrobial polyamide/silver nanocomposites," Applied Physics A, vol. 91, no. 3, pp. 479-486, 2008.

[6] M. Jokar, R. Abdul Rahman, N. A. Ibrahim, L. C. Abdullah, and C. P. Tan, "Melt production and antimicrobial efficiency of lowdensity polyethylene (LDPE)-silver nanocomposite film," Food and Bioprocess Technology, vol. 5, no. 2, pp. 719-728, 2012.

[7] Y. M. Mohan, T. Premkumar, K. Lee, and K. E. Geckeler, "Fabrication of silver nanoparticles in hydrogel networks," Macromolecular Rapid Communications, vol. 27, no. 16, pp. 1346-1354, 2006.

[8] T. B. Karchmer, E. T. Giannetta, C. A. Muto, B. A. Strain, and B. M. Farr, "A randomized crossover study of silver-coated urinary catheters in hospitalized patients," Archives of Internal Medicine, vol. 160, no. 21, pp. 3294-3298, 2000.

[9] C. Marambio-Jones and E. M. V. Hoek, "A review of the antibacterial effects of silver nanomaterials and potential implications for human health and the environment," Journal of Nanoparticle Research, vol. 12, no. 5, pp. 1531-1551, 2010.

[10] S. Tripathi, G. K. Mehrotra, and P. K. Duttta, "Chitosan-silver oxide nanocomposite film: preparation and antimicrobial activity," Bulletin of Materials Science, vol. 34, no. 1, pp. 29-35, 2011.

[11] L. Timochenco, G. V. Grassi, M. Dal Pizzol et al., "Swelling of organoclays in styrene. Effect on flammability in polystyrene nanocomposites," Express Polymer Letters, vol. 4, no. 8, pp. 500508, 2011.

[12] R. P. Singh, A. Tiwari, and A. C. Pandey, "Silver/polyaniline nanocomposite for the electrocatalytic hydrazine oxidation," Journal of Inorganic and Organometallic Polymers and Materials, vol. 21, no. 4, pp. 788-792, 2011.

[13] J. R. Morones, J. L. Elechiguerra, A. Camacho et al., "The bactericidal effect of silver nanoparticles," Nanotechnology, vol. 16, no. 10, pp. 2346-2353, 2005.

[14] O. Choia, K. K. Deng, N.-J. Kim, L. Ross Jr., R. Y. Surampalli, and $\mathrm{Z}$. Hu, "The inhibitory effects of silver nanoparticles, silver ions, and silver chloride colloids on microbial growth," Water Research, vol. 42, no. 12, pp. 3066-3074, 2008.

[15] T. Hamouda, A. Myc, B. Donovan, A. Y. Shih, J. D. Reuter, and J. R. Baker Jr., "A novel surfactant nanoemulsion with a unique non-irritant topical antimicrobial activity against bacteria, enveloped viruses and fungi," Microbiological Research, vol. 156, no. 1, pp. 1-7, 2000.

[16] I. Sondi, B. Salopek-Sondi, S. D. Škapin, S. Šegota, I. Jurina, and B. Vukelić, "Colloid-chemical processes in the growth and design of the bio-inorganic aragonite structure in the scleractinian coral Cladocora caespitosa," Journal of Colloid and Interface Science, vol. 354, no. 1, pp. 181-189, 2011.
[17] P. Dibrov, J. Dzioba, K. K. Gosink, and C. C. Häse, "Chemiosmotic mechanism of antimicrobial activity of $\mathrm{Ag}^{+}$in Vibrio cholerae," Antimicrobial Agents and Chemotherapy, vol. 46, no. 8, pp. 2668-2670, 2002.

[18] I. Dragieva, S. Stoeva, P. Stoimenov, E. Pavlikianov, and K. Klabunde, "Complex formation in solutions for chemical synthesis of nanoscaled particles prepared by borohydride reduction process," Nanostructured Materials, vol. 12, no. 1-4, pp. 267270, 1999.

[19] N. A. Amro, L. P. Kotra, K. Wadu-Mesthrige, A. Bulychev, S. Mobashery, and G. Liu, "High-resolution atomic force microscopy studies of the Escherichia coli outer membrane: structural basis for permeability," Langmuir, vol. 16, no. 6, pp. 2789-2796, 2000 . 

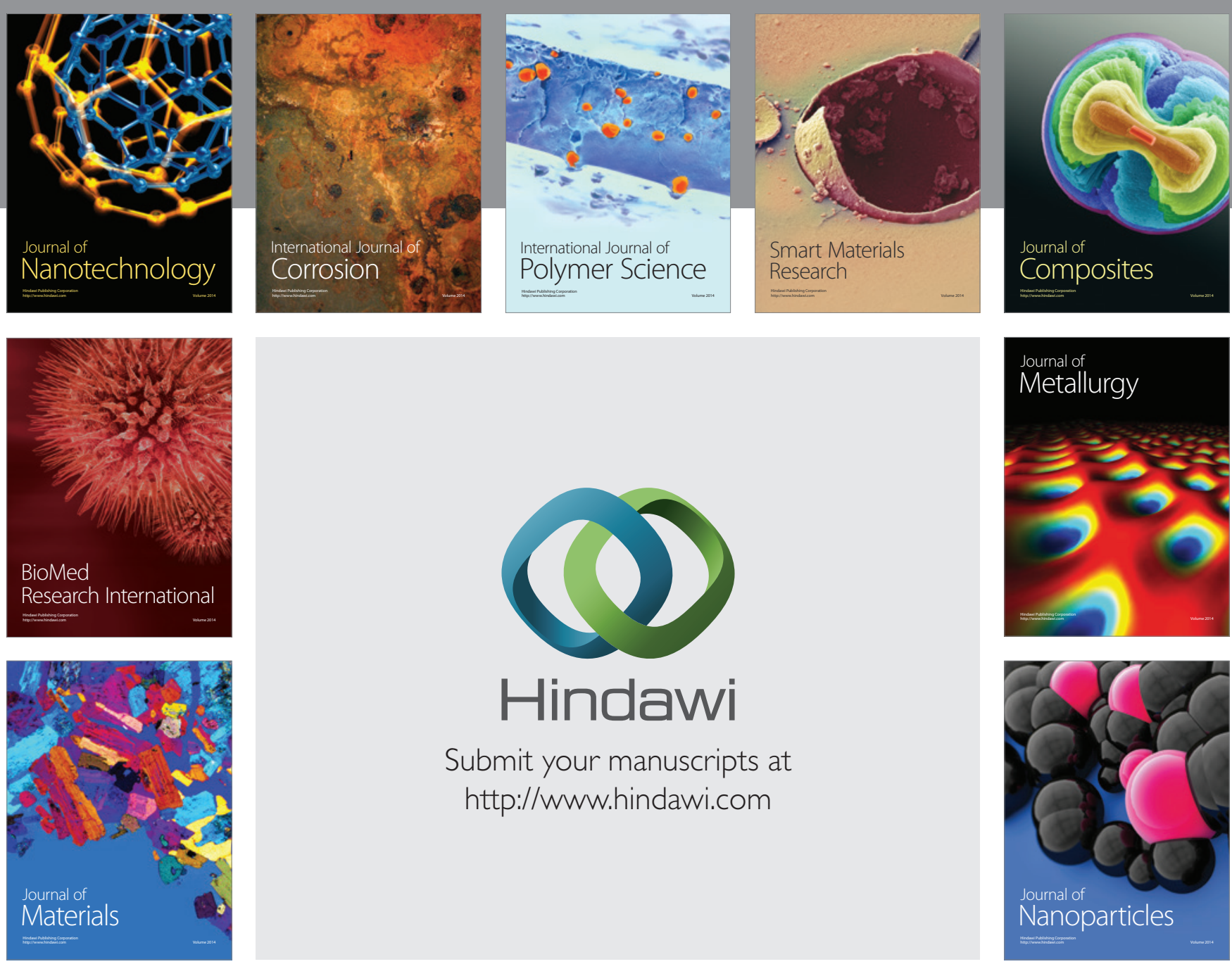

Submit your manuscripts at http://www.hindawi.com
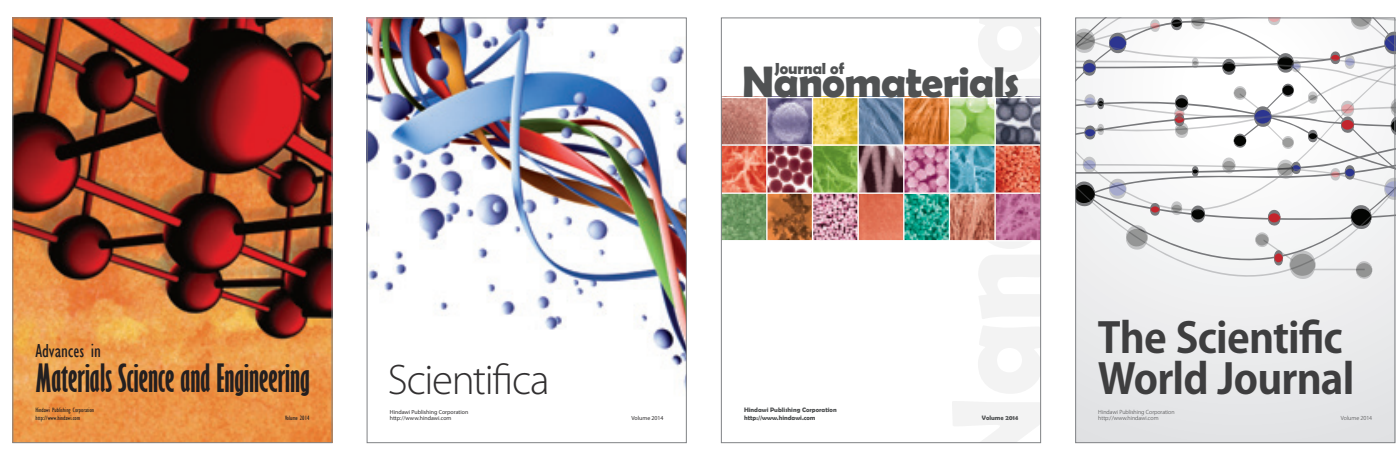

\section{The Scientific World Journal}
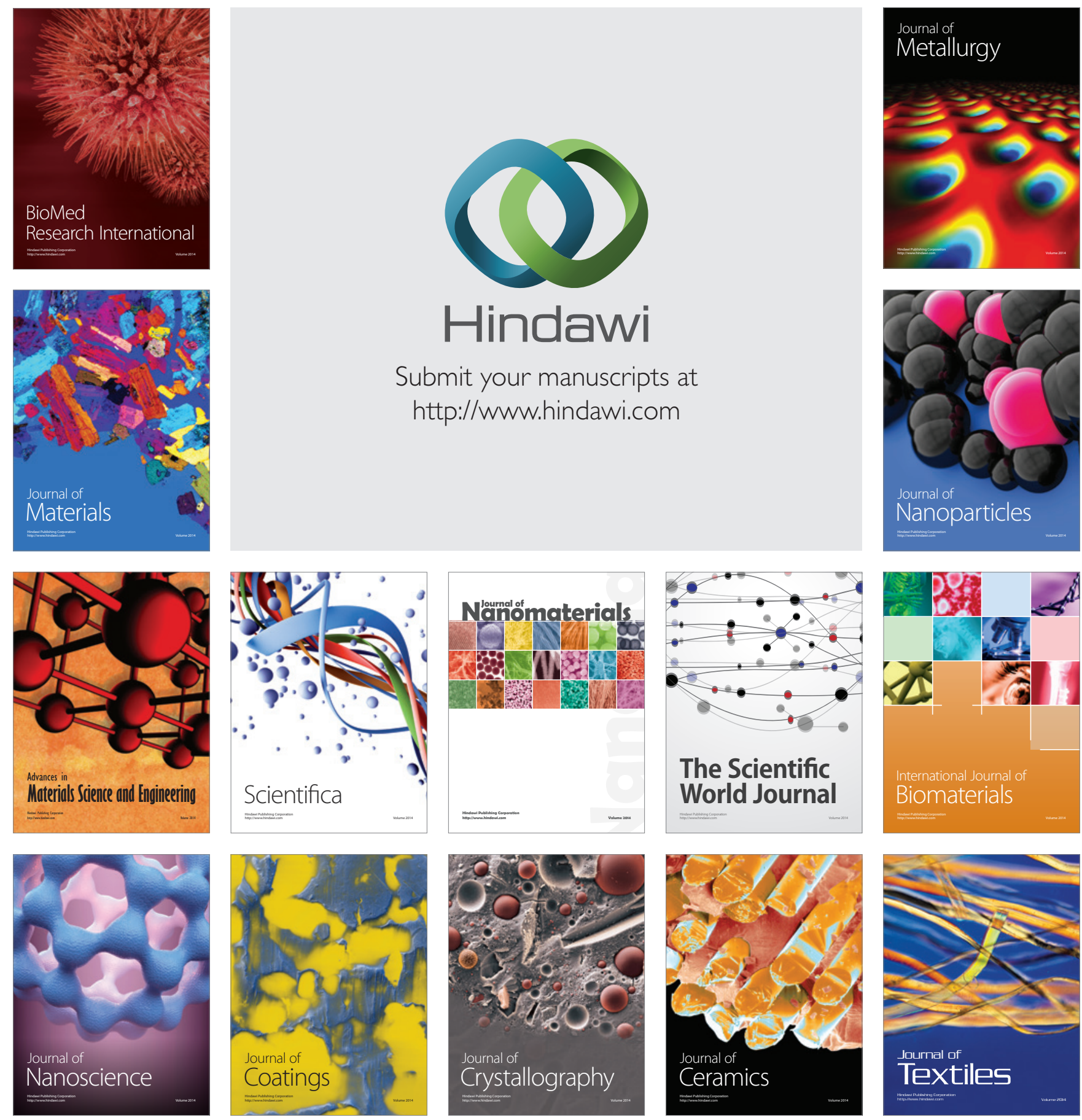